\title{
RELECTURA DE UNA CANTIGA DE AMIGO
}

\begin{abstract}
La seule nécessité véritable sur ce plan-là, c'est l'incessante re-définition que j’évoquais plus haut. C'est la remise en cause, à tout instant, de la relation existant entre le moyenâge et le médiéviste, entre ce vieux texte et son lecteur érudit.
\end{abstract}

PAui. Zumtuor, Parler du molen-âge

En 1976 se publicó en Lisboa, en una edición muy hermosa y cuidada, un libro titulado Do Cancioneiro de Amigo, que reúne tres artículos de autores diferentes y cincuenta cantigas de amigo, junto con comentarios '. El libro seduce porque a su belleza tipográfica y de diseño añade la modernidad de un enfoque metodológico y teórico capaz de llevara un plano más científico las discusiones sobre las cantigas de amigo de la tradición gallego-portuguesa medieval, que hasta entonces habian sido más bien especulativas. En sus artículos, Stephen Reckert, Roman Jakobson y Helder Macedo presentan intentos de aplicación de métodos formalistas a las cantigas de amigo, analizando, por ejemplo, el empleo de los tiempos verbales en algún poema (Reckert) o las secuencias fónicas en otro (Jakobson). El nuevo enfoque ha producido una obra fascinante, que al mismo tiempo plantea un problema teórico y epistemológico fundamental: el de la posibilidad de aplicar métodos contemporáneos de análisis literario (fundados en concepciones actuales del lenguaje, de la literatura, de las relaciones entre forma y fondo, etc.) a textos que, conceptual y culturalmente, están tan lejos de nosotros como las cantigas de amigo. Cuestión previa que los tres autores evitan tratar, pero que percibimos como algo de suma urgencia al recorrer sus análisis.

'S. Reckerty H. Macedo, Do Cancioneiro de Amigo, Assirio e Alvim, Lisboa, 1976. Los ensayos son: S. ReCKERT, “A variação subliminar na poética de cantiga" (pp. 7-34), R. JAkobson, “A textura poética de Martim Codax"(pp. 35-48), y H. MAcedo, "Uma cantiga de Dom Dinis" (pp. 49-60), y van seguidos de 50 cantigas de amigo, con comentarios de S. Reckert. Sólo hay una edición completa de las cantigas de amigo, la de José Jonquim NuxEs. Es de 1928 y ya fue reeditada sin ninguna modificación en 1973 por el Centro do Livro Braisileiro en Lisboa. 
Este problema previo será examinado aquí a propósito de uno de los poemas más célebres de la tradición gallego-portuguesa, un alba cuyo texto completo es el siguiente ${ }^{2}$ :

Levad', amigo que dormides as manhãas frias; toda-las aves do mundo d'amor diziam:

leda m' and' eu.

Levad', amigo que dormide-las frias manhăas toda-las aves do mundo d'amor cantavam; leda m' and' eu.

Toda-las aves do mundo d'amor diziam: do meu amor e do voss' emmentariam; leda m' and" eu.

Toda-las aves do mundo d'amor cantavam: do meu amor e do voss' i emmentavam; leda m' and'eu.

Do meu amor e do voss'emmentariam; vós thi tolhestes os ramos em que siiam: leda m' and' eu.

Do meu amor e do voss'i emmentavam; vós lhi tolhestes os ramos en que pousavam: leda m' and' eu.

Vós lhi tolhestes os ramos em que siiam, e lhis secastes as fontes em que beviam: leda m' and' eu.

Vós lhi tolhestes os ramos em que pousavam, e lhis secastes as fontes u se banhavam: leda m' and' eu.

La interpretación más comúnmente aceptada es que el poema está compuesto de dos partes claramente distintas. La primera parte - feliz - va de la primera estrofa a la cuarta y evoca la dicha de la noche pasada con el amante, el canto amoroso de las aves. Luego hay una ruptura: la segunda parte, formada por las cuatro estrofas finales, es infeliz. El corte de las ramas y la desecación de las fuentes de agua se consideran como signos del fin del amor. Queda el problema del estribillo que, por su naturaleza, es idéntico a todo lo largo de un poema, pero que suena totalmente falso en la segunda parte del alba que nos ocupa. La explicación tradicional de esta aparente incoherencia es que se trata del canto de una doncella que, en su inocencia, todavía no se da cuenta de que su amante ha decidido abandonarla definitivamente. Ignorante de su suerte, sigue procla mando su alegría ("alegre me voy") y utiliza el presente del indicativo del verbo cuando ya todo pertenece al pasado. Pero esta interpretación, artificial y aleatoria, no se ve confïmada por ningún hecho textual.

2 Do Cancioneiro, p. 24; en J.J. Nunes, op. cit., pp. 71-72. 
Reckert analiza esta alba ${ }^{3}$ tomando como punto de partida la alternancia de los tiempos verbales. Al enfocar este aspecto del poema, crea una perspectiva prometedora para la solución del problema de la incoherencia en el texto (¿o en la interpretación más común, o en las dos?), causada, como hemos visto, por el presente del indicativo del estribillo en un contexto donde todo pertenece ya al pasado.

De entrada, Reckert subdivide el texto en tres partes:

1. El marco idílico de las cuatro primeras estrofas, presentado y situado en el presente de indicativo. Hay además cinco imperfectos ${ }^{4}$ que Reckert califica como perfectos "faz de conta" (literalmente, haz de cuenta), equivalentes a un presente de indicativo. Justifica esta modificación bastante arbitraria del imperfecto refiriéndose a algunos juegos de niños en que supuestamente se hace lo mismo.

2. La ruptura de las estrofas cinco y seis que, por la introducción del pretérito simple, presentan una situación acabada. El pretérito simple sirve al mismo tiempo como "modificante" 5 del imperfecto/presente de la primera parte, que recupera aquí su función convencional de describir una situación en pasado. Incluso los imperfectos de la primera parte son modificados retrospectivamente para pasar a ser imperfectos convencionales. El presente del estribillo, en este lugar, se explica por la ingenuidad de la doncella, inconsciente aún de su desgracia.

3. El pasado irrecuperable de las estrofas siete y ocho, donde predomina el pretérito simple. El pretérito simple sirve aquí de "modificante" del presente del estribillo, que se convierte en un "presente falso" y por ello transforma el significado literal del estribillo -leda m' and' eu- en su contrario: la añoranza y la amargura irónica de la mujer abandonada. Todo ello se transporta después a un marco más amplio ${ }^{6}$.

El silencio de los pájaros, en el momento en que despierta la mujer, es interpretado como una huida, comparable a su vez con la del amante que huye de este amor que ya no tiene ningún atractivo para él.

3 Do Cancioneiro, pp. 24-29 y 123-125.

Es cierto que en los juegos de niños (tanto españoles como franceses, alemanes, holandeses, etc.) es bastante frecuente este empleo del imperfecto con valor de presente de indicativo. Pero, desde el punto de vista metodológico, es inadmisible que su frecuencia en los juegos infantiles constituye en sí un argumento para interpretar de igual manera textos de naturaleza diferente, y sobre todo si se trata de un texto como "Levad' amigo", un alba que se considera como uno de los textos más cultos de los cancioneiros. Por consiguiente, mi crítica a Reckert se dirige únicamente contra la facilidad con la que sugiere una interpretación que no es evidente, sin dar ninguna prueba precisa. Reckert, sin justificar su elección, interpreta el verso 8 del manuscrito como si hubiera un futuro del pasado: emmentariam. J.J. Nunes propone "en ment' avian", es decir, otro imperfecto.

"Reckert toma el concepto de "modificante" de Carıos Bousoño, Teoría de la expresión poética, Madrid, 1952. No entraremos a discutir aquí si Bousoño emplea este concepto en el sentido que le da Reckert en Do Cancioneiro.

${ }^{6}$ Cf. Do Cancioneiro, pp. 123-125. 
La frescura de la aurora se convierte en el frío de los amaneceres de otoño, símbolo del enfriamiento del amor.

Una conclusión inevitable es que la interpretación de Reckert complica aún más el esquema interpretativo tradicional, al utilizar el concepto de "modificante" para justificar tres momentos clave de sú interpretación: a) la transformación en presente de los cinco imperfectos del principio del poema; b) el pretérito simple de la segunda parte que transforma retrospectivamente los imperfectos de la primera en imperfectos convencionales; c) el pretérito simple de la tercera parte que cambia el presente del estribillo, convirtiéndolo en presente falso, es decir, en imperfecto.

Estas modificaciones se explican con la ayuda de tres artificios que parecen otras tantas hazañas: la primera modificación se justifica remitiéndonos a los juegos infantiles; el presente de la segunda parte, por la supuesta ingenuidad de la doncella, y el de la tercera, por un cambio radical del significado del estribillo, que pasa de la alegría a la ironía y la amargura.

Por lo tanto, el análisis formalista de Reckert no sale de los marcos prestablecidos de la interpretación más comúnmente aceptada del poema. No resuelve la contradicción interna del texto, ni la incoherencia de la interpretación más común, a la que, en el fondo, no hace más que aumentar.

Antes de abordar el análisis crítico del método de Reckert, tratemos de saber si sería posible interpretar el poema de otra manera.

Releyéndolo cuidadosamente, se descubren en él dos símbolos muy antiguos de la literátura ibérica, y quizás incluso de las literaturas de todas las lenguas indoeuropeas: el de la fuente de agua viva y el de la rama verde.

El simbolismo de la fuente de agua viva en la literatura ibérica ha sido estudiado por E. Asensio ${ }^{7}$, pero existió en toda Europa. Asensio demuestra que el culto de las fuentes es muy antiguo, y que el agua es el arquetipo por excelencia de la sexualidad y de la fecundidad femeninas. Beber el agua fría de una fuente que la creencia popular consideraba sagrada era un rito secular destinado a estimular la fecundidad, como se ve en esta canción sefardí:

E. Astisio, "Fonte frida o encuentro del romance con la canción de mayo", Poéti'a y realidad en el cancionero peninsular de la Edad Media, Gredos, Madrid, 1957, pp. 241-277; J.M. Blásquez, "Le culte des eaux dans la Péninsule Ibérique", Ogam, Rennes, 9 (1957), 209-233; F. Crespo, "A tradiçāo de uma lírica popular portuguesa antes e depois dos trovadores", Ocid, 71 (1966), 185-204; J. LeITE DE VAscovcelos, Etnografia portuguesa, 1967, t. 5, 124-140. Cf. también Gaston BACHELARD, L'eau et les rềes. Essais sur l'imagination de la matière. Corti, Paris, 1947; G. Dursid, Les structures anthropologiques de l'imaginaire. Introduction à l'archétypologie générale, $4^{a}$ ed.. Bordas, Paris, 1974, pp. 103-122; Werner Daxckert, Symbol, Metapher. Allegorie im Lied der Völker, Verlag für systematische Musikwissenschaft, Bonn-Bad Godesberg, 1977, 4 ts. 
Dezía el aguadero: - Niña chiquita,

allí está la fuente del agua viva;

novia que de ella bebe, al año parida ${ }^{8}$.

Esperar al amante al pie de la fuente, encontrarlo ahí, beber juntos el agua fría antes de hacer el a mor, constituía un acto má gico de anticipación nupcial, considerado por los dos amantes y por la comunidad de la que formaban parte como una promesa inviolable y sagrada de fidelidad recíproca. A ello se debe que en la poesía medieval encontremos tan a menudo el arquetipo femenino del agua en compañía de símbolos fálicos, tales como el del ciervo o el ruiseñor que han enturbiado el agua?.

También el culto de los árboles estaba muy extendido ${ }^{10}$. Cada región tenía sus árboles sagrados, tales como el roble anglosajón, el tilo germánico, el avellano francés, la "avelaneira" y el "pinho" gallego-port ugueses. Esos árboles o arbustos estaban revestidos de poderes má gicos. En primavera, las mujeres se reunían bajo ellos para bailar danzas eróticas que constituían invitaciones dirigidas a los jóvenes para realizar juegos eróticos. Esto se ve, por ejemplo, en los Carmina Burana:

Congregatur augmentatur
cetus iuvenum
adunator colletatur
chorus virginum
et sub tilia
ad choreas venereas
salit mater inter eas
sua filia.

Así bailaban las mujeres en la tradición gallego-portuguesa bajo los avellanos o bajo los pinos. Encontramos muy a menudo en esos textos la expresión "o ramo verde" como sinónimo de los árboles. Del abeto, por ejemplo ${ }^{11}$ :

$$
\begin{aligned}
& \text { O anel do meu amigo } \\
& \text { perdi-o so lo verde pinho } \\
& \text { e chor'eu bela! }
\end{aligned}
$$

\footnotetext{
${ }^{8}$ En A. Sávchez Romeralo, El villancico. (Estudios sobre la lírica popular en los siglos xw r xil), Gredos, Madrid, 1969, p. 336.

F. Mexdez, Ferrix, O Cancioneiro de Pero Meogo, Vigo, 1966, pp. 54-110; Jole Scudieri-Rugigieri, "Alle fonti della cultura ispanovisigotica", Studi Medievali, 16 (1943-1950), 1-47.

11) El libro más completo sobre el culto de los árboles en Europa es el de W. MANxHARDI, Wald-und Feldkulte, Berlin, 1875; cf. también P. DroNke, The medievallyric, Hutchinson, London, 1968. En el capitulo iv, "Dance songs", analiza el simbolismo del avellano.

1 En J.J. Nuxes, op. cit., pp. 238-239.
} 
$O$ anel do meu amado

perdi-o so lo verde ramo

e chor'eu bela!

En ciertos poemas el paso del árbol a la rama se hace progresivamente, como en esta "bailada" bajo el avellano, de la cual cito los dos primeros versos de cada estrofa ${ }^{12}$ :

Bailemos nós já todas tres, ai amigas, so aquestas avelaneiras frolidas

Bailemos nós já todas tres, ai irmåas, so aqueste ramo d'estas avelāas

...........

Por Deus, ai amigas, mentral non fazemos, so aqueste ramo frolido bailemos

..........

Las muchachas que deseaban entrar en contacto con el joven de su elección se sentaban debajo de un árbol sagrado, lugar predilecto de encuentro con el amante. En muchas regiones de Europa existía la costumbre siguiente: el hombre, antes de pasar al acto sexual, debía cortar una rama de uno de esos árboles y ofrecérsela a la mujer. Era un acto preñado de consecuencias jurídicas y estaba considerado, en la comunidad tradicional, como una promesa sagrada de fidelidad. El alemán Bóckel ${ }^{13}$ dedicó un estudio al valor jurídico y simbólico del acto de cortar una rama verde de un árbol sagrado. Una canción popular alemana dice, por ejemplo ${ }^{14}$ :

Da brach der Ritter einen grü nen Zweig Und machte das Mädchen zu seinem Weib.

Ahora se comprende mejor el significado de esta canción popular gallega:

Qu'a rula que viodou

Xurou de non ser casada

Nin pouser en ramo verde

Nin beber d'augua erara.

La que no quiera casarse no tomará iniciativas sexuales como sentarse bajo un árbol sagrado, aceptar̀ una rama verde, o beber agua de la fuente con un hombre.

Ibid., p. 235.

${ }^{3}$ O. Böckel, Deutsche Volkslieder aus Oberhessen, Marburg, 1885. Da ejemplos de varios países de Europa, pp. xxii-xxiv.

${ }^{14}$ lbid., p. Xxv, ("Entonces el caballero cortó una rama verde / Y a la doncella, la hizo su mujer"). 
Al releer ahora el poema "Levad' amigo..." nos damos cuenta de que bajo las formas más bien cultas de esta poesía bien podrían ocultarse los dos actos mágicos y sagrados que acabamos de analizar. Si es así, la doncella, después de haber pasado la noche con su amante, se va feliz con buena razón: se ha cumplido con todo lo que había que hacer para que la unión fuera sagrada a sus propios ojos y a los de la comunidad en que viven: el amante cortó la rama y bebió en la fuente de agua clara, antes de hacer el amor con ella. El canto de los pájaros, entonces, también adquiere un significado diferente ${ }^{15}$. En las sociedades medievales, los pájaros (sobre todo el ruiseñor) eran considerados como agentes mágicos en los asuntos de amor, y su canto, como un estímulo erótico. Ahora bien, todo el mundo sabe que los pájaros se callan en la fría hora de la mañana que antecede a la salida del sol, precisamente la hora en que despierta la mujer del alba que nos ocupa.

Además, el canto amoroso de los pájaros siempre se asocia, al igual que el poder mágico del agua y de los árboles, con la renovación de la primavera. Por lo tanto, no hay ninguna razón para situar la fría mañana en otoño, como lo hace Reckert.

Hay en el poema un elemento estilístico muy notable que lo distingue de la mayoría de las cantigas de amigo: las exageraciones o hipérboles, tales como la expresión "toda-las aves do mundo", los plurales "os ramos" y "as fontes" y el verbo "secastes" (vaciaste la fuente). Estas hipérboles podrían traducir el entusiasmo y la dicha exultante de la mujer que, al momento del despertar, se da cuenta de que todos sus sueños se han vuelto realidad.

Si volvemos ahora al análisis de los tiempos verbales, es claro que sólo hace falta leerlos en sus funciones convencionales para descubrir un orden coherente y una estructura interna lógica, al tiempo que dividimos el poema en tres partes, como lo hace Reckert:

1-4: el despertar feliz, cuando renace el recuerdo del ambiente amoroso de la noche pasada con el amante ( 8 presentes de indicativo y 8 imperfectos);

5-6: al recuerdo del ambiente amoroso se añade el de los actos mágicos realizados (4 imperfectos y 2 pretéritos simples);

7-8: felicidad exultante al recordar los actos mágicos realizados (predomina el pretérito simple).

is Sobre el simbolismo del canto de los pájaros, véase W. Hevsel, Die Vögel in der provenzalischen und nordfranzösischen L.irik, tesis, Königsberg, 1908; J.M. B1.ECUA, Los pájaros en la poesia española, Madrid, 1943, y un libro que se debe leer con extrema circunspección, pero que of rece una riquísima fuente de datos interesantes: Alfred Schossig, Der Ursprung der altfranzösischen Lyrik, Halle, 1957, pp. 61-144. 
Pret.

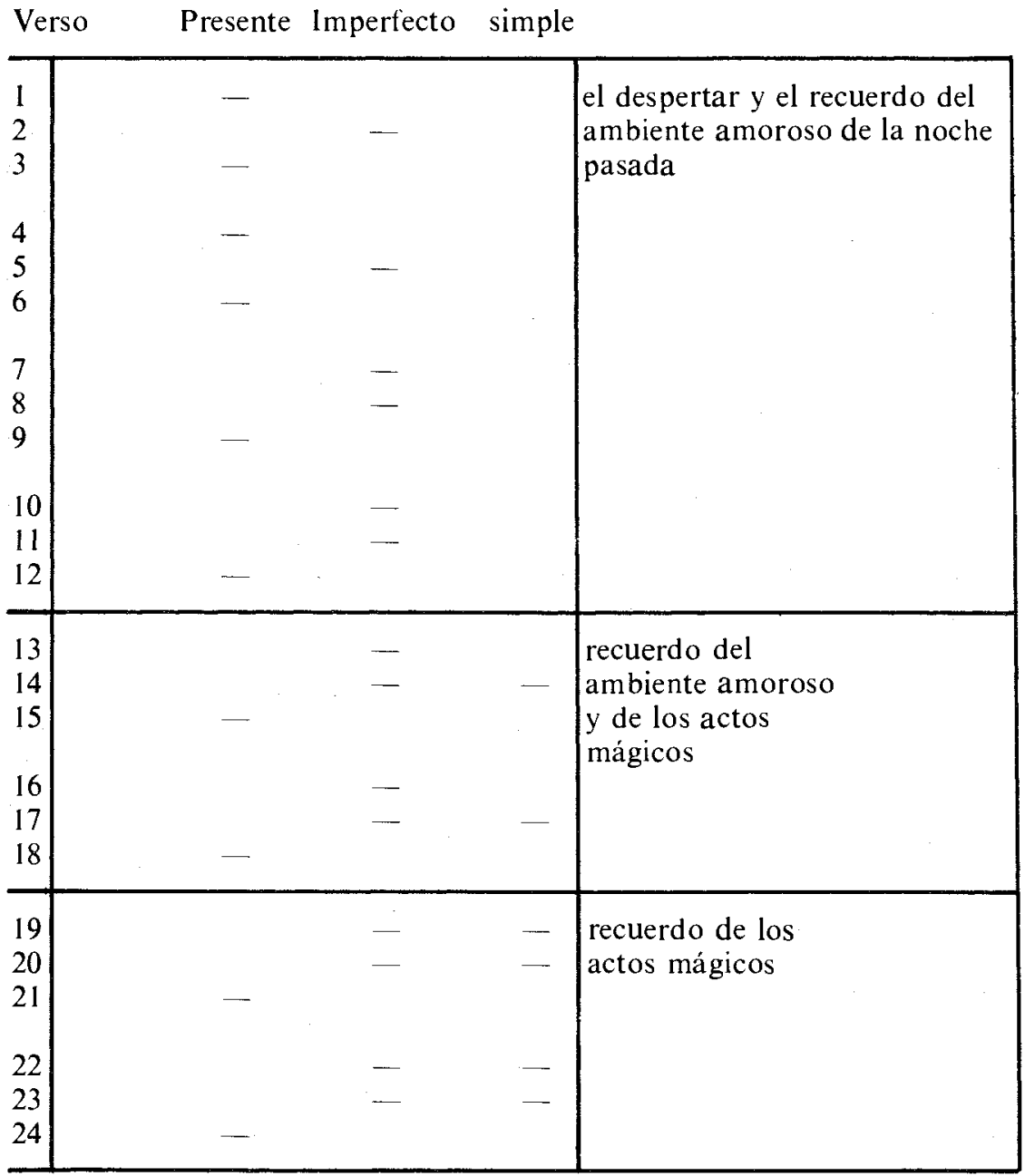

Volviendo a la crítica del análisis formalista de Reckert, debemos preguntarnos cuáles son los elementos estructurales sobre los que se funda.

Hay, en primer lugar, una concepción doble de la naturaleza. Unas veces es vista como locus amoenus (el canto de los pájaros, los árboles, la fuente), otras como espejo de los estados de ánimo humanos (el frío de la mañana de otoño como signo de la muerte del amor). Son dos concepciones de la naturaleza que, en las literaturas en lenguas romances, sólo asumirán su pleno sentido después de la Edad Media; una en la época del Renacimiento, la otra en el Romanticismo.

También la concepción de la mujer es específica: es una doncella ingenua que se deja seducir con facilidad. El amor se concibe como una felicidad pasajera que no lleva a mayores consecuencias. 
Lo que se oculta subrepticiamente y con cierta sofisticación, detrás de la interpretación del crítico literario, es un gran tópico de la literatura occidental: el del acto sexual realizado por el hombre en plena naturaleza con una mujer (de preferencia una doncella, virgen, e ingenua) a la que aband ona después del acto. Sueño eterno del hombre occidental, que tan bien conocemos gracias a la literatura y a las obras de arte que nos ha legado, desde la pastorela medieval ${ }^{16}$.

La interpretación propuesta en este artículo remite a un mundo y una cultura que ya no existen, y en los que las concepciones de la vida, del hombre y de la naturaleza eran completamente diferentes de las actuales. La naturaleza aún era mágica y estaba cargada de un erotismo expresado con símbolos arcaicos; todavía no se desacraliza como en la sociedad occidental moderna.

El amor en ese mundo es feliz y está perfectamente integrado a la comunidad en la que viven los dos a mantes; se realiza siguiendo ritos seculares que le confieren un carácter tanto mágico como religioso. Este tópico ha desaparecido en la literatura moderna, donde el amor generalmente es desdichado y está en conflicto con la sociedad. Los dos seres humanos son conscientes de sus responsabilidades mutuas. Es un tópico que ya no está de moda en el arte occidental, en el cual el hombre en general es seductor o adorador espirit ual y la mujer, objeto erótico o dama inaccesible ${ }^{17}$.

Considerando todos estos elementos, se puede sostener que la interpretación de Reckert sigue siendo prisionera de los presupuestos de su autor y confirma así, a pesar de su supuesta objetividad científica, estructuras mentales, concepciones del hombre y del mundo, que no existían en esa forma en la Edad Media, y que son las de un erudito del siglo $\mathrm{xx}$.

¿Cuáles serían, después de todo lo dicho, las conclusiones a las que se podría llegar? Un crítico literario ha intentado aplicar un método de análisis formalista a un texto medieval. Pero no lo hizo considerando solamente el texto, sino que emprendió su tarea sin dejar de lado todo un bagaje cultural y literario que contenía, entre otros, un marco de interpretación preexistente, una tradición que no interroga y que determina la naturaleza misma de las preguntas que va a hacer al texto.

De esta manera, el método formalista se utiliza - como por ejemplo en el caso del concepto de modificante - para justificar incoherencias

it En 1972 tue publicado un fascinante estudio de Michel. ZNk dedicado a este tópico: La pastourelle. Poésie et folklore au molen-àge, Bordas, Paris-Montreal. Para situar este tópico en la historia de las ideas de la civilización occidental, véase M. BERNHEIMER, Wild men in the Middle Ages, Harvard University Press, Cambridge, Mass., 1952; E. Dudtey and M. Novak, ed., The wild man within. An image in Western thought from the Renaissance to Romanticism, Pittsburgh, 1972.

17 Ct. Sitvia Bovevschex, Die imaginierte Weiblichkeit. Exemplarische Untersuchungen zu kulturgeschichtlichen und literarischen Präsentationsformen des Weiblichen, Suhrkamp, Frankfurt, 1979. 
en la interpretación propuesta y, a más largo plazo, para confirmar ideológicamente, por medio de un texto medieval, concepciones del mundo, del hombre y de la naturaleza que pertenecen al crítico y a su época. ¿Se debe concluir entonces que es preferible no aplicar métodos formalistas a textos medievales? La conclusión sería prematura puesto que, como lo hemos visto en el caso examinado, el método ha sido mal aplicado.

Lo que queda claro, al menos, es el peligro de aplicar un método formalista a poemas medievales separados del contexto cultural y literario en el que tuvieron su origen.

Lo que también queda claro es que hay condiciones elementales que se deben cumplir antes de hacer análisis formalistas de textos aislados, tales como un conocimiento profundo de la civilización y de la sociedad de la Edad Media, así como de las imágenes y los símbolos de su literatura. Pero también hace falta tener conocimientos tan extensos como sea posible de los tópicos, temas, imágenes y símbolos de las demás literaturas en lenguas romances (e incluso indoeuropeas en general) y de la literatura popular de períodos posteriores.

Por último, y esto es lo esencial, se necesita tener una conciencia aguda y lúcida de las limitaciones de nuestros conceptos y concepciones modernos y una voluntad deliberada de proceder a ese permanente cuestionamiento "de la relation existant entre le moyen age et le médiéviste, entre ce vieux texte et son lecteur érudit"18.

RIA LEMAIRE

Traducción de Flora Botton-Burlá.

18 Panl Zumthor, Parler du moven-âge, Les Éditions de Minuit, Paris, 1980, p. 27. 